ARTICLE

\title{
Atomic-scale unveiling of multiphase evolution during hydrated Zn-ion insertion in vanadium oxide
}

Pilgyu Byeon (10) ${ }^{1}$, Youngjae Hong ${ }^{1}$, Hyung Bin Bae ${ }^{2}$, Jaeho Shin ${ }^{3}$, Jang Wook Choi (D) ${ }^{3 凶}$ \& Sung-Yoon Chung (D) ${ }^{1 凶}$

An initial crystalline phase can transform into another phases as cations are electrochemically inserted into its lattice. Precise identification of phase evolution at an atomic level during transformation is thus the very first step to comprehensively understand the cation insertion behavior and subsequently achieve much higher storage capacity in rechargeable cells, although it is sometimes challenging. By intensively using atomic-column-resolved scanning transmission electron microscopy, we directly visualize the simultaneous intercalation of both $\mathrm{H}_{2} \mathrm{O}$ and $\mathrm{Zn}$ during discharge of $\mathrm{Zn}$ ions into a $\mathrm{V}_{2} \mathrm{O}_{5}$ cathode with an aqueous electrolyte. In particular, when further $\mathrm{Zn}$ insertion proceeds, multiple intermediate phases, which are not identified by a macroscopic powder diffraction method, are clearly imaged at an atomic scale, showing structurally topotactic correlation between the phases. The findings in this work suggest that smooth multiphase evolution with a low transition barrier is significantly related to the high capacity of oxide cathodes for aqueous rechargeable cells, where the crystal structure of cathode materials after discharge differs from the initial crystalline state in general.

\footnotetext{
${ }^{1}$ Department of Materials Science and Engineering and KAIST Institute for the Nanocentury, Korea Advanced Institute of Science and Technology, Daejeon, Korea. ${ }^{2}$ KAIST Analysis Center, Korea Advanced Institute of Science and Technology, Daejeon, Korea. ${ }^{3}$ School of Chemical and Biological




A lthough Li-ion batteries have been used as a major rechargeable power source since 1991, safety and longstanding cost issues from the utilization of Li have been routinely raised. This has led researchers to seek alternative intercalation chemistry to $\mathrm{Li}$ without using flammable organic electrolytes. Various aqueous batteries operated using earthabundant redox cations have been suggested over the last two decades in response to this ${ }^{1-7}$. As metallic $\mathrm{Zn}$ with a high capacity can be used as an anode together with a water-based nonflammable aqueous solution as an electrolyte, $\mathrm{Zn}$-ion aqueous rechargeable batteries have attracted a surge of attention over the last several years ${ }^{1,2,7-9}$. In particular, it was recently demonstrated that noticeable capacities of more than $300 \mathrm{mAh} \mathrm{g}^{-1}$ and thousands of cycles can be achieved in $\mathrm{V}_{2} \mathrm{O}_{5}$ and other $\mathrm{V}$-based oxides as cathode materials in aqueous $\mathrm{Zn}$-ion batteries ${ }^{2,7,10-23}$. Despite these notable electrochemical properties especially for large-scale applications, in-depth understanding of the Zn-intercalation behavior and the origin of high capacities and reversibility in vanadium oxides under an aqueous environment remains seriously lacking, whereas there have been numerous reports focusing on the cycling performance.

Atomic-column-resolved scanning transmission electron microscopy (STEM) with spherical aberration correction has been extensively utilized as a suitable analysis tool over the last decade to probe the local structure and composition variations in intercalated oxides for energy storage ${ }^{24-32}$. In this work, we intensively use STEM in (high-angle) annular dark-field ((HA) $\mathrm{ADF}$ ) and annular bright-field (ABF) modes ${ }^{33-42}$ to precisely identify both the site occupancy of $\mathrm{Zn}$ and $\mathrm{H}_{2} \mathrm{O}$ and the multiphase evolution in $\mathrm{V}_{2} \mathrm{O}_{5}$ during discharge of $\mathrm{Zn}$ ions under an aqueous condition. More importantly, as $\mathrm{Zn}$ insertion proceeds further, the presence of multiple intermediate topotactic phases, which cannot be identified by macroscopic powder diffraction, is directly reveled at an atomic scale. The remarkable reversible capacity and cyclability of $\mathrm{V}_{2} \mathrm{O}_{5}$ thus appear to have a strong correlation with the topotactically smooth transformation between the charged and discharged phases via the intermediate transient states. The findings in this study suggest that the availability for facile multiphase transitions during charge/discharge may be an important condition for cathode materials with high capacity and reversibility in aqueous rechargeable batteries, where the crystal structure of discharged cathodes comprehensively differs from its initial crystalline state in general.

\section{Results}

$\mathrm{X}$-ray diffraction analysis. Prior to atomic-scale observation, we carried out an X-ray powder diffraction analysis to examine the phase evolution during discharge. Figure 1a shows a series of diffraction patterns together with a voltage profile during $\mathrm{Zn}$ intercalation into $\mathrm{V}_{2} \mathrm{O}_{5}$ particles. Each of the patterns was obtained at a different discharge voltage. This set of results indicates the formation of two new phases during discharge, as denoted by red and green diamonds in the diffraction patterns. Figure $1 b-d$ provide enlargements within $2 \theta$ ranges for the Bragg reflections of the new phases. First, left-hand shifts of the $\mathrm{V}_{2} \mathrm{O}_{5}$ (200) and (301) peaks upon discharging are observed (Fig. 1c, d) from the beginning to $0.95 \mathrm{~V}$, directly demonstrating the lattice parameter increment of solid-solution $\mathrm{V}_{2} \mathrm{O}_{5}$ with $\mathrm{Zn}$ and thereby a gradual drop in the voltage profile in Fig. 1a. In addition, as a new $\mathrm{Zn}$-intercalation phase, $\mathrm{Zn}_{x} \mathrm{~V}_{2} \mathrm{O}_{5}$ (green diamonds), is generated at $0.95 \mathrm{~V}$, the two phases, solid-solution $\mathrm{V}_{2} \mathrm{O}_{5}$ and $\mathrm{Zn}_{x} \mathrm{~V}_{2} \mathrm{O}_{5}$, coexist in the voltage range of $0.95-0.77 \mathrm{~V}$ (see Supplementary Fig. 1 for details on the phase identification of $\mathrm{Zn}_{x} \mathrm{~V}_{2} \mathrm{O}_{5}$ including $\mathrm{X}$-ray diffraction simulations). As another discharged product, a hydrated $\mathrm{Zn}_{y} \mathrm{~V}_{2} \mathrm{O}_{5} \cdot n \mathrm{H}_{2} \mathrm{O}$ (red diamond) phase finally appears at $0.77 \mathrm{~V}$ (Fig. 1b), in agreement with the Xray diffraction results reported in previous studies ${ }^{10,11}$ (see Supplementary Fig. 2 for details on the (001) peak identification of $\left.\mathrm{Zn}_{y} \mathrm{~V}_{2} \mathrm{O}_{5} \cdot n \mathrm{H}_{2} \mathrm{O}\right)$. It is also intriguing that the Bragg reflections of the discharged phases $\left(\mathrm{Zn}_{x} \mathrm{~V}_{2} \mathrm{O}_{5}\right.$ and $\left.\mathrm{Zn}_{y} \mathrm{~V}_{2} \mathrm{O}_{5} \cdot n \mathrm{H}_{2} \mathrm{O}\right)$ show a peak shift (green and red broken lines in Fig. 1b-d) during discharge, indicative of solid-solution behavior. More importantly, as denoted by black arrows in Fig. 1c, d, small shoulder peaks around the major Bragg reflections of $\mathrm{Zn}_{x} \mathrm{~V}_{2} \mathrm{O}_{5}$ are detectable as well, although their intensity is fairly low. This strongly implies that the discharge reaction may not be simply based on the three distinct phases but rather is associated with multiple-phase complex evolution.

STEM analyses with thin films. To scrutinize the phase evolution during discharge, we prepared polycrystalline $\mathrm{V}_{2} \mathrm{O}_{5}$ thin films deposited on a conductive $\mathrm{SnO}_{2}$-coated glass substrate instead of using randomly oriented particle-type samples for efficient STEM observation. Figure 2a shows the overall film configuration on a conductive $\mathrm{SnO}_{2}$-coated substrate (see Supplementary Fig. 3 for the X-ray diffraction pattern and the chemical composition of the films). As can be seen in the bright-field (BF) STEM image and its enlargement, a polycrystalline microstructure was well developed. When the film was observed at a higher magnification, $\mathrm{V}_{2} \mathrm{O}_{5}$ grains and their boundaries were readily identified. A pair of $\mathrm{ABF}$ and HAADF STEM images in Fig. $2 b$ exemplifies two adjacent grains and their boundary, which is a typical crystal-crystal interface with no intergranular phase (see Supplementary Fig. 4 for additional sets of images showing grain boundaries). The lower grain denoted as "Grain II" in the HAADF image is aligned in the [010] projection. Therefore, as shown in the atomiccolumn image together with the schematic illustration for the atom position in Fig. $2 \mathrm{~b}$, the structural feature showing the layered $\left[\mathrm{VO}_{5}\right]$ slabs and interstitial empty sites between the slabs is easily recognized in this $b$-axis projection.

As the conductive $\mathrm{SnO}_{2}$ coating on a glass substrate acts as a current collector, $\mathrm{Zn}$ ions are electrochemically inserted into each of the grains through grain boundaries in the film. Indeed, galvanostatic charge/discharge profiles could be obtained when the thin-film sample was electrochemically cycled with a $1 \mathrm{M}$ $\mathrm{ZnSO}_{4} / \mathrm{H}_{2} \mathrm{O}$ electrolyte (see Supplementary Fig. 5a). Figure $2 \mathrm{c}$ presents a typical discharge profile acquired from the film at a constant current density. An intriguing aspect during the composition analysis of the film after the discharge reaction is that a notably higher concentration of $\mathrm{Zn}$ was identified in the grain-boundary regions, as demonstrated by the energy dispersive X-ray spectroscopy (EDS) maps in Fig. 2d. This compositional information indicates that $\mathrm{Zn}$-ion diffusion along grain boundaries is much faster than the bulk diffusion, as expected in general (see Supplementary Fig. 5b, c for an additional set of EDS maps and line profiles). An X-ray photoemission spectroscopy (XPS) analysis also verifies the presence of $\mathrm{Zn}$ as well as the reduction of $\mathrm{V}$ by $\mathrm{Zn}$ insertion (see Supplementary Fig. 6 for the XPS results). Figure 2e shows an HAADF image (upper) acquired from a $\mathrm{Zn}$-rich grainboundary region in addition to an image of the $\mathrm{V}_{2} \mathrm{O}_{5}$ bulk grain (lower). As indicated by the X-ray diffraction pattern showing a fairly broad width of the (001) peak (red diamond) at the final stage of discharge in Fig. 1b, a significantly low degree of crystallinity could be consistently identified, representing the hydrated $\mathrm{Zn}_{y}$ $\mathrm{V}_{2} \mathrm{O}_{5} \cdot n \mathrm{H}_{2} \mathrm{O}$ phase. An additional set of wide-view images for this $\mathrm{Zn}$-rich discharged phase is provided in Supplementary Fig. 7. Although the results shown in Fig. 2d, e were obtained from a thinfilm discharged to $0.47 \mathrm{~V}$, a similar $\mathrm{Zn}$ distribution and the presence of a low-crystallinity phase in the grain-boundary regions in a film 
discharged to $0.77 \mathrm{~V}$ were observed during the STEM analysis (see Supplementary Figs. 8-11).

Atomic-column-resolved observations. We first observed the center of a grain in the $b$-axis projection, as indicated by the red rectangle in the HAADF image in Fig. 3a. In agreement with Fig. 2b, the atomic-scale HAADF image in Fig. $3 \mathrm{~b}$ verifies that each of the $\mathrm{V}$ columns is straightforwardly resolved in this projection. The most striking feature in Fig. $3 \mathrm{~b}$ is that many interstitial sites showing a bright contrast by the $\mathrm{Zn}$ intercalation differ from the previously known interstitial sites that other cations, such as $\mathrm{Li}$ and $\mathrm{Mg}$, occupy. For clarification, an enlargement of the location denoted by a yellow rectangle in Fig. $3 \mathrm{~b}$ is provided in Fig. 3c. Previous reports on $M_{x} \mathrm{~V}_{2} \mathrm{O}_{5}(M=\mathrm{Li}, \mathrm{Mg} ; x \leq 1)$, prepared via electrochemical intercalation or chemical syntheses, have demonstrated that the cations, $M$, locate at the doubletrigonal (M1) interstitial sites ${ }^{43-49}$, as represented by white spheres in the schematic illustrations in Fig. $3 \mathrm{~d}$. In contrast, our observation directly shows that a majority of $\mathrm{Zn}$ ions in our sample unusually occupy the pyramidal (M2) interstitial sites (see yellow arrows in Fig. 3c), as represented by yellow spheres in the schematic illustration in Fig. 3e.

Based on the Fourier transform infrared (FTIR) spectroscopy of our thin-film sample after the discharge reaction for $\mathrm{Zn}$ intercalation, a substantial absorption peak at a wavelength of $\sim 3200 \mathrm{~cm}^{-1}$ was detected (see Supplementary Fig. 12). As it is known that this peak stems from the vibrational absorbance of $\mathrm{O}-\mathrm{H}$ stretching, the FTIR results indicate the insertion of $\mathrm{H}_{2} \mathrm{O}$ molecules into the lattice
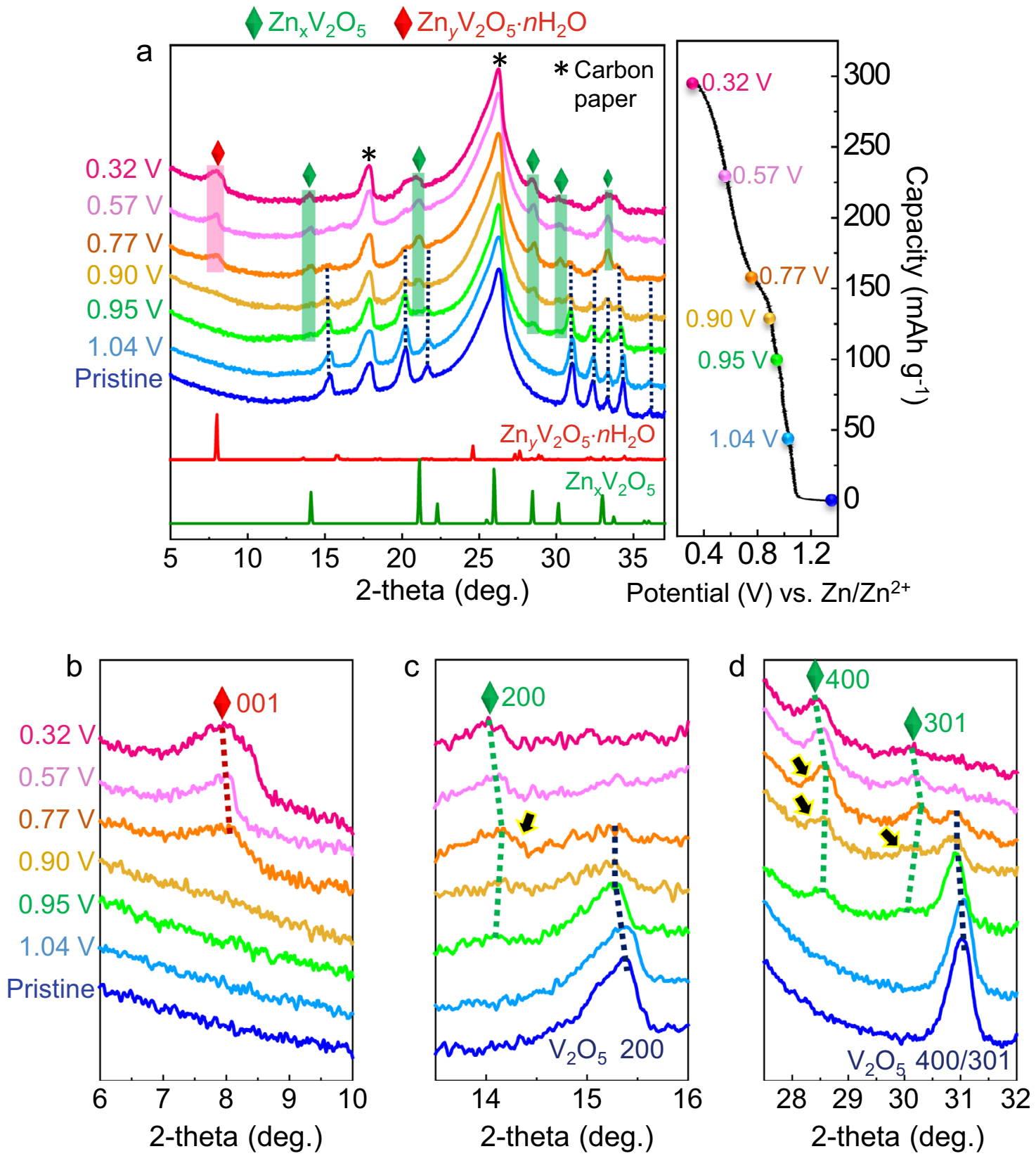

Fig. 1 Series $\mathbf{X}$-ray powder diffraction patterns of $\mathbf{V}_{\mathbf{2}} \mathbf{O}_{\mathbf{5}}$. a Each ex situ diffraction pattern was obtained at a different discharge voltage, as indicated in the galvanostatic voltage profile. The generation of two $\mathrm{Zn}$-containing phases $\left(\mathrm{Zn}_{x} \mathrm{~V}_{2} \mathrm{O}_{5}\right.$ and $\left.\mathrm{Zn}_{y} \mathrm{~V}_{2} \mathrm{O}_{5} \cdot n \mathrm{H}_{2} \mathrm{O}\right)$ during discharge is identified, as denoted by green and red diamonds. Details of the phase identification are provided in Supplementary Figs. 1 and 2. b-d The narrow-range enlargements are shown for the major Bragg peaks of the discharged phases. Shifts of the peak position during discharge directly indicate the change in lattice parameters and thereby solidsolution behavior. Black arrows denote unidentified small shoulder peaks, implying multiple-phase discharge reactions. 

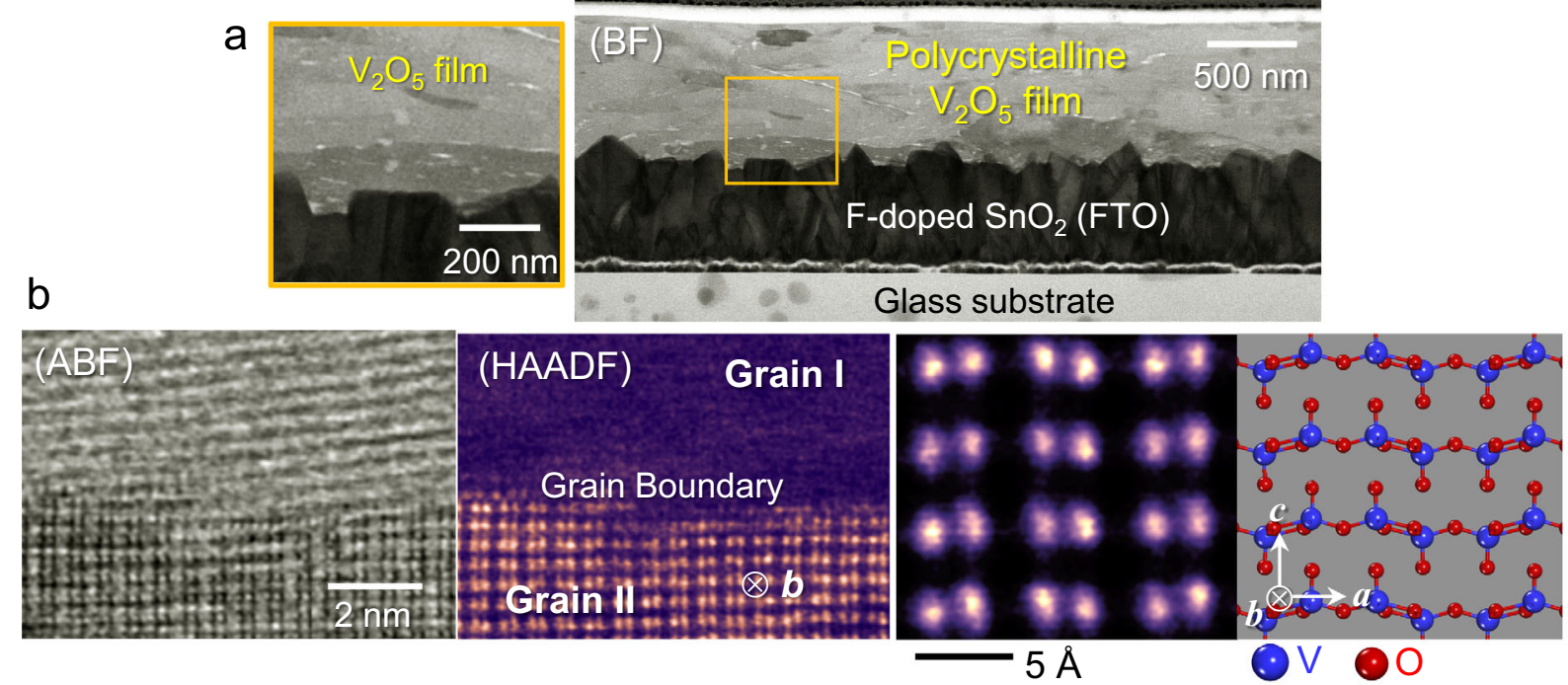

C

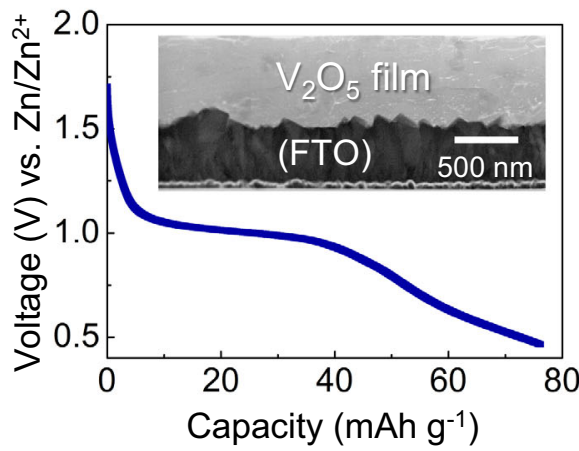

d
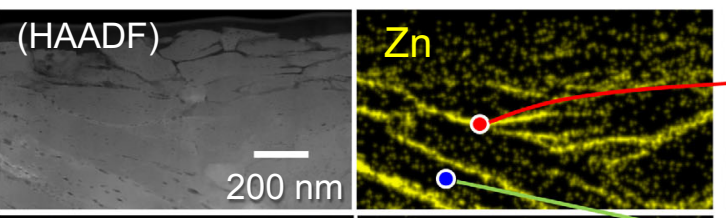

e
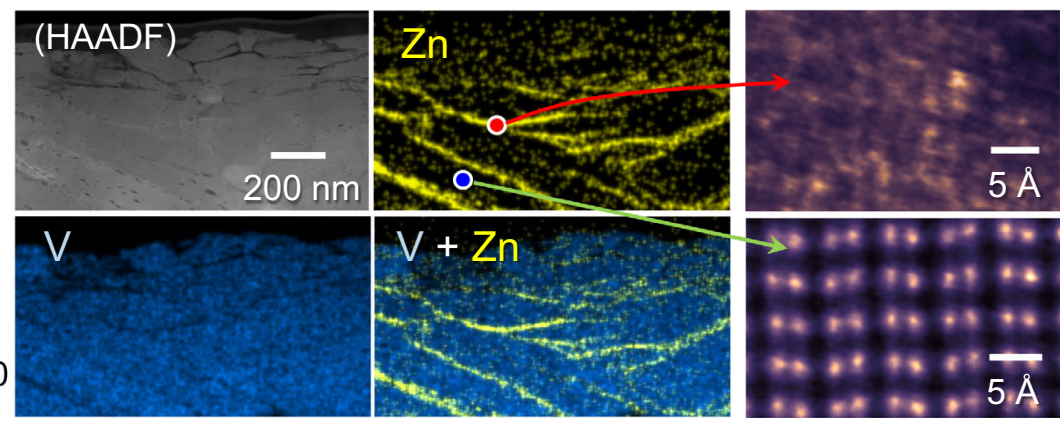

Fig. $2 \mathbf{V}_{\mathbf{2}} \mathbf{O}_{\mathbf{5}}$ thin-film deposition and electrochemical $\mathbf{Z n}$ insertion. a The BF-STEM image and its enlargement show the polycrystalline microstructure of the $\mathrm{V}_{2} \mathrm{O}_{5}$ film deposited on a glass substrate coated with $\mathrm{F}$-doped $\mathrm{SnO}_{2} \cdot \mathbf{b}$ A grain-boundary region is magnified in a pair of ABF and $\mathrm{HAADF}$ images. Grain II is aligned in the [010] projection, as shown in the atomic-column-resolved image along with a schematic illustration for atom positions. $\mathbf{c} A$ discharge profile demonstrates the electrochemical $\mathrm{Zn}$ insertion into the $\mathrm{V}_{2} \mathrm{O}_{5}$ thin film. $\mathbf{d} A$ set of EDS maps also verifies the presence of $\mathrm{Zn}$, showing a much higher $\mathrm{Zn}$ concentration in grain-boundary regions. This sample was discharged to $0.47 \mathrm{~V}$. e Two atomic-scale images taken from the grain bulk (lower) and a $\mathrm{Zn}$ rich grain-boundary (upper) are compared to consistently show the low crystallinity of the hydrated $\mathrm{Zn}_{y} \mathrm{~V}_{2} \mathrm{O}_{5} \cdot n \mathrm{H}_{2} \mathrm{O}$ phase.

during the discharge ${ }^{17}$. We thus simultaneously acquired HAADF and $\mathrm{ABF}$ images to directly visualize $\mathrm{H}_{2} \mathrm{O}$ in addition to high atomic-number $(\mathrm{Z})$ cations. As indicated by yellow arrows in the HAADF image in Fig. 3f, additional bright contrast showing $\mathrm{Zn}$ intercalation at the pyramidal M2 sites could be verified, in agreement with Fig. 3c. More importantly, while no intensity above the background noise is detected at the double-trigonal M1 sites in the HAADF image, substantial black (or gray) contrast is observed in the ABF image in Fig. 3f, as emphasized by red arrows. The clear $\mathrm{M} 1$-site contrast in the $\mathrm{ABF}$ image provides direct atomic-scale evidence of the $\mathrm{H}_{2} \mathrm{O}$ insertion.

To verify the intercalation of $\mathrm{Zn}$ and $\mathrm{H}_{2} \mathrm{O}$, a series of image simulations in the HAADF and ABF modes were performed by using the multislice method ${ }^{50}$. As demonstrated in Supplementary Fig. 13, imaging at an under-focus condition in the ABF mode with thin samples ( $\leq 5 \mathrm{~nm}$ in thickness) failed to visualize the oxygen columns. We thus simultaneously obtained all the HAADF and ABF images in in-focus or slightly over-focus conditions to achieve sufficient contrast. The simulated ABF images in Fig. 3g support that the contrast of $\mathrm{H}_{2} \mathrm{O}$ can be clearly captured when the $\mathrm{H}_{2} \mathrm{O}$ occupation in the $\mathrm{M} 1$ sites is $\geq 50 \%$. The whole series of (HA)ADF and $\mathrm{ABF}$ image simulations with the occupation variation of $\mathrm{Zn}$ and $\mathrm{H}_{2} \mathrm{O}$ are also provided in Supplementary Figs. 14 and 15, respectively. Good agreement between the experimentally acquired and simulated images is noted in Fig. 3f (see Supplementary Fig. 16 for each of the specific $\mathrm{Zn}$ and $\mathrm{H}_{2} \mathrm{O}$ occupation factors adopted in the image simulations), revealing the unusual site occupancy of $\mathrm{Zn}$ and the position of $\mathrm{H}_{2} \mathrm{O}$ molecules in $\mathrm{V}_{2} \mathrm{O}_{5}$. In addition, as demonstrated by the electron-density isosurface obtained by ab initio density functional theory (DFT) calculations in Fig. 3h, the $\mathrm{H}_{2} \mathrm{O}$ molecule acts as the nearest ligand and thus constructs a weak bond with $\mathrm{Zn}$. Consequently, the presence of $\mathrm{H}_{2} \mathrm{O}$ as crystal water ${ }^{17,51,52}$ appears to play a critical role in stabilizing the $\mathrm{Zn}$ occupancy at the pyramidal M2 site, strongly supporting hydrated Znintercalation during discharge. More details on the DFT calculations are included in Supplementary Fig. 17.

To consolidate our observation of the $\mathrm{H}_{2} \mathrm{O}$ intercalation at the $\mathrm{M} 1$ sites, additional sets of simultaneously obtained $\mathrm{ABF}$ and HAADF images in both the [010] and the [001] projections are provided in Fig. 4. While the M1 sites are identified to be empty in pristine films in both projections, substantial column contrast is clearly detected at some M1 interstices exclusively in the ABF images, not in the HAADF images. The contrast feature appearing only in $\mathrm{ABF}$ mode thus consistently supports the presence of $\mathrm{H}_{2} \mathrm{O}$ with low atomic numbers. Raw ABF images without band-pass filtering are also provided in Fig. 4 to clarify that this image aspect is not affected by filtering. Inverse-intensity 
b

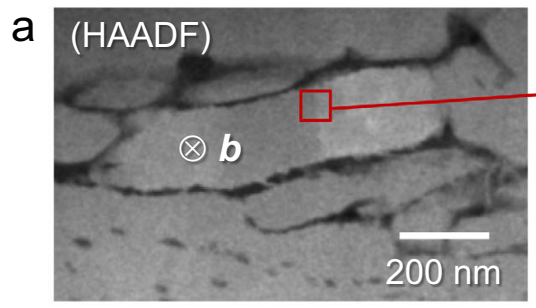

a

d $\odot v \odot o$

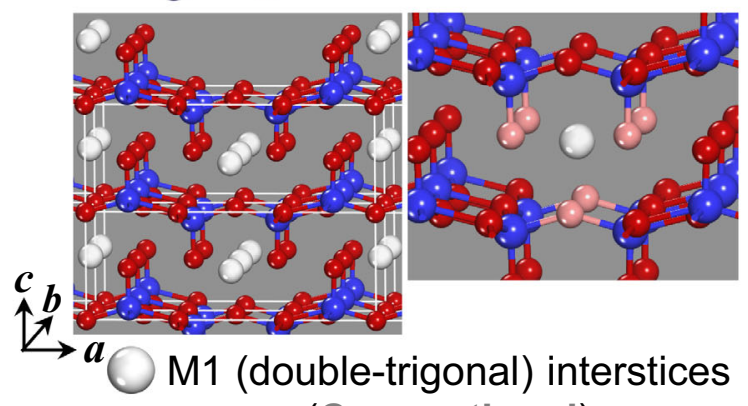

(Conventional)

f

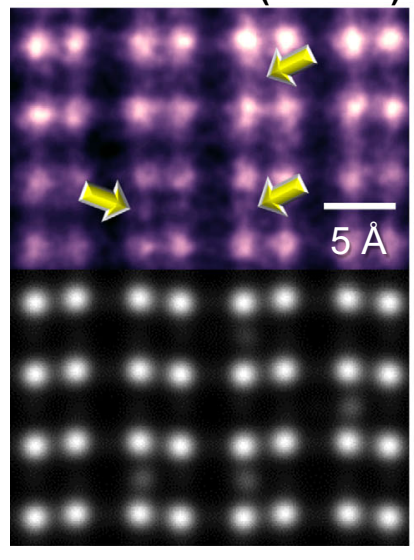

$\mathrm{Zn}$ at $\mathrm{M} 2$ sites; $\mathrm{H}_{2} \mathrm{O}$ at $\mathrm{M} 1$ sites
C

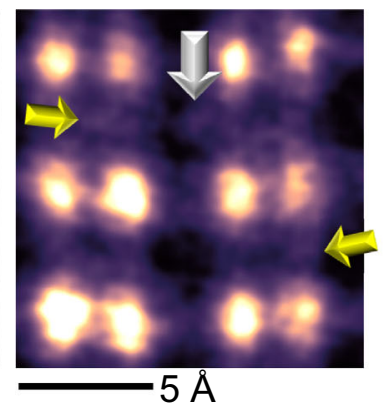

e

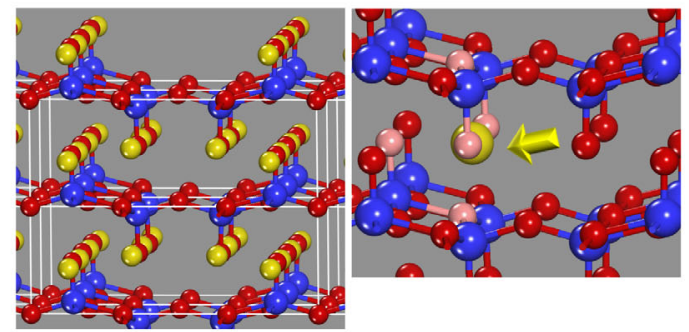

M2 (pyramidal) interstices

(New)

(ABF)


$\mathrm{h}$

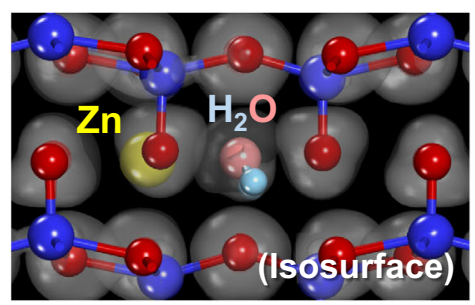

Fig. 3 Direct visualization of $\mathbf{Z n}$ and $\mathbf{H}_{\mathbf{2}} \mathbf{O}$ insertion. a The HAADF image shows the polycrystalline microstructure of the discharged film ( $0.77 \mathrm{~V}$ ). $\mathbf{b}$ In addition to the $V$ columns, another bright contrast is identified in this atomic-level image. A yellow rectangle indicates the typical location for the additional contrast between the $\mathrm{V}$ columns. $\mathbf{c} \mathrm{A}$ magnified image is provided for the location in $\mathbf{b}$. Each of the white and yellow arrows indicates a detectable contrast from the two crystallographically distinct interstitial sites in $\mathrm{V}_{2} \mathrm{O}_{5}$. d, e The double-trigonal $\mathrm{M} 1$ and pyramidal $\mathrm{M} 2$ interstices are denoted by white and yellow spheres in the illustrations, respectively. Nearest-neighboring oxygens of each interstice are depicted by light-red spheres. $\mathbf{f}$ The yellow arrows verify the unconventional $\mathrm{Zn}$ occupancy at the $\mathrm{M} 2$ sites. While there is no bright contrast at the M1 sites in the HADDF image, a black contrast is clearly observed in the $\mathrm{ABF}$ image (red arrows). This reveals $\mathrm{H}_{2} \mathrm{O}$ insertion. The simulated images are in good agreement with the real images. $\mathbf{g}$ ABF image simulations with $\mathrm{H}_{2} \mathrm{O}$ occupancy demonstrate that visible contrast of $\mathrm{H}_{2} \mathrm{O}$ can be captured when the occupancy is $\geq 50 \%$. $\mathbf{h}$ The isosurface contour of electron-density difference is illustrated with a $\mathrm{H}_{2} \mathrm{O}$ molecule as a ligand, demonstrating the stabilization of $\mathrm{Zn}$ at the $\mathrm{M} 2$ site.

ABF images obtained in the [001] projection are shown in Supplementary Fig. 18 for better visualization of the presence of $\mathrm{H}_{2} \mathrm{O}$.

Multiple phase transformations. The key finding in this work was acquired when we examined the high $\mathrm{Zn}$-concentration regions near grain boundaries. Figure $5 \mathrm{a}, \mathrm{b}$ show ADF images of $\mathrm{V}_{2} \mathrm{O}_{5}$ grains in the $b$ - and $c$-axis projection, respectively. The magnified regions with a high $\mathrm{Zn}$ concentration, as denoted by a red rectangle in each projection, were scrutinized. Two series of atomic-column-resolved ADF images taken from locations 1 to 5 in each grain in Fig. $4 \mathrm{c}$, d directly prove the multiphase transformation at a nanoscale. A detectable intensity is exhibited at many of the atomic columns for the pyramidal interstitial M2 sites in location 2, indicating a substantial amount of intercalated $\mathrm{Zn}$ in the $\mathrm{Zn}_{x} \mathrm{~V}_{2} \mathrm{O}_{5}$ phase. The most significant observation from Fig. 5 is that the presence of intermediate states $\left(\mathrm{VO}_{2}(\mathrm{~A})\right.$-type and rocksalt $\mathrm{VO}$-type structures), which are very difficult to detect by macroscopic powder diffraction, is clearly identifiable at atomic resolution, as revealed in the images for locations $3-5$. The structure observed in location 3 in both projections matches well with that of $\mathrm{VO}_{2}(\mathrm{~A})$ among many polymorphisms found in $\mathrm{VO}_{2}$ (see Supplementary Fig. 19 

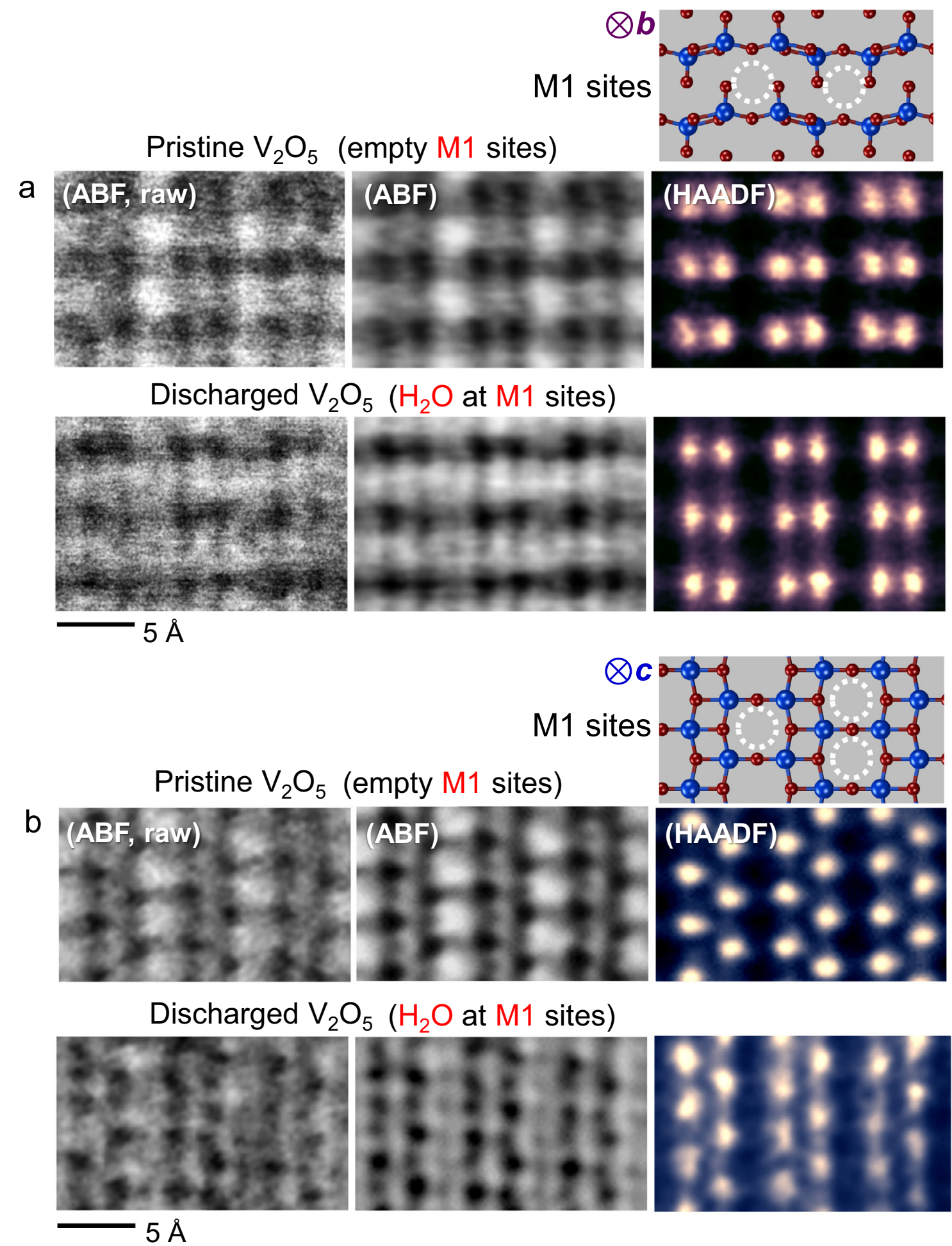

Fig. 4 STEM images in two projections to visualize the presence of $\mathbf{H}_{\mathbf{2}} \mathbf{O}$. a When neither $\mathrm{Zn}$ nor $\mathrm{H}_{2} \mathrm{O}$ intercalates, no additional contrast appears in either the HAADF or ABF image in this projection. A black contrast is clearly observed at the M1 sites in the ABF image of a discharged sample. This reveals the $\mathrm{H}_{2} \mathrm{O}$ insertion at the $\mathrm{M} 1$ sites. $\mathbf{b}$ These sets of images were acquired in the [001] projection. A substantial black contrast in the ABF image of a discharged sample consistently demonstrates the presence of $\mathrm{H}_{2} \mathrm{O}$ at the $\mathrm{M} 1$ interstice.

for the polymorphisms). Yellow arrows in the images for location 4 denote intercalated $\mathrm{Zn}$ in the interstitial sites in the $\mathrm{VO}_{2}(\mathrm{~A})$-type structure. On the basis of the atomic configuration in the images of locations 3 and 4 in both projections, the crystal structure of locations 3 and 4 appears to be basically an identical $\mathrm{VO}_{2}(\mathrm{~A})$ type, showing that many of the interstitial sites are filled with $\mathrm{Zn}$ at location 4 as a solid solution. The rocksalt-type VO structure in both projections is also found in location 5. As reported in a recent study on a vanadium oxide ${ }^{53}$ in addition to other Li-intercalated metal oxides ${ }^{26,27,30}$, the rocksalt structure having cations in every octahedral site in the close-packed oxygen-anion framework appears to be a local 

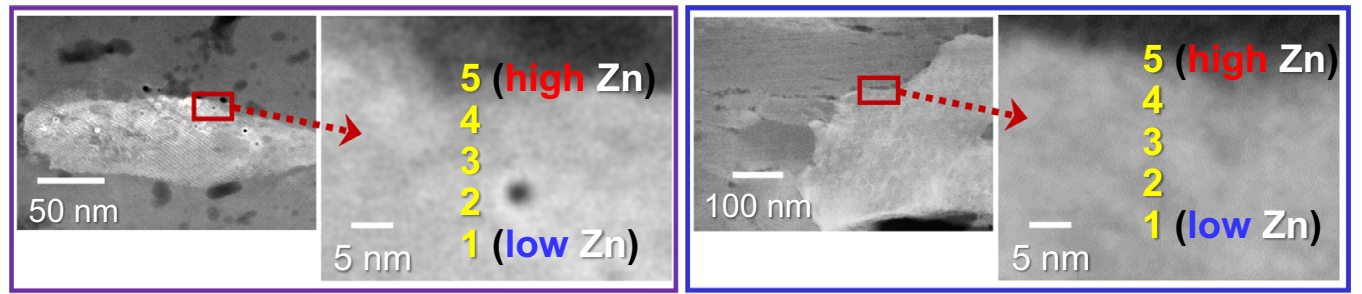

\section{c}

$\otimes b \quad 1 \quad 2$

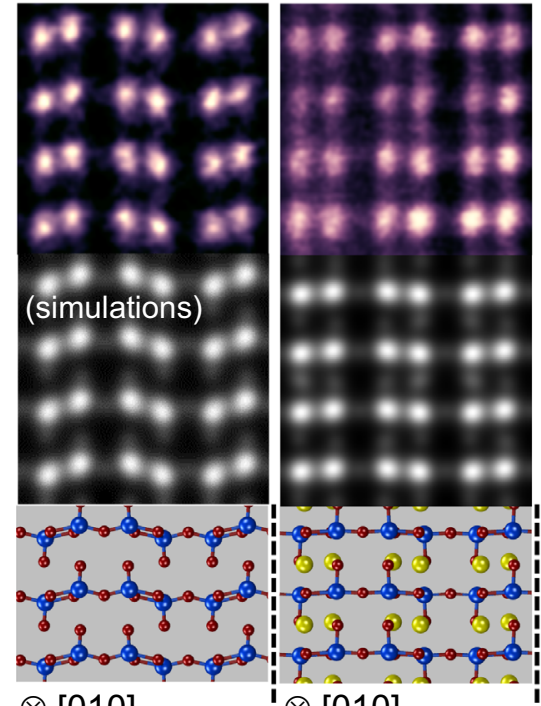

23

34

$4 \quad 5$
$\otimes[010]$
$\otimes[010]$
$\otimes[001]$
$\alpha-\mathrm{V}_{2} \mathrm{O}_{5} \cdot . \mathrm{Zn}_{x} \mathrm{~V}_{2} \mathrm{O}_{5} * . .1$
$\otimes[001]$
$\otimes[010]$
$\mathrm{VO}_{2}(\mathrm{~A})$ type
. . Rocksalt type

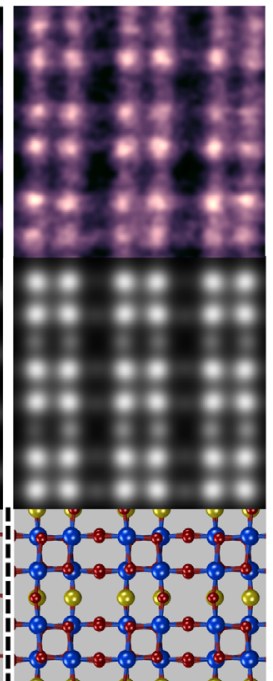

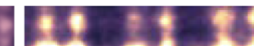

5
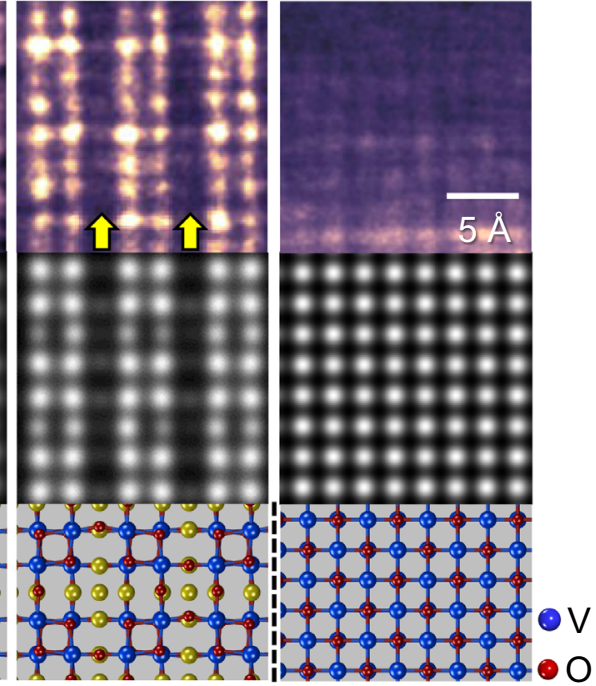

$\otimes c$

1

2

d

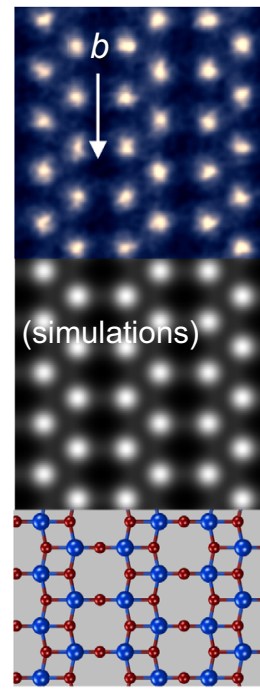

$\otimes[001]$

$\rightarrow$

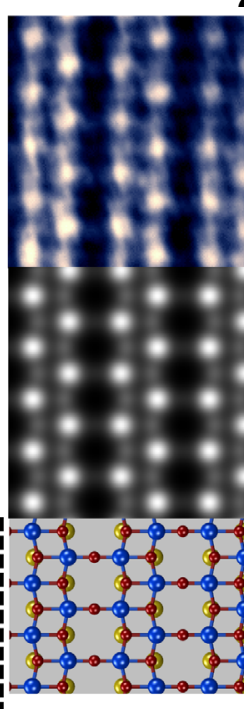

3

4

5



Fig. 5 Topotactic multiphase transformations. a, b This sample was discharged to $0.77 \mathrm{~V}$. Boundary regions of grains in both $b$ - and c-axis projections were observed, as denoted by a red rectangle in each projection. A larger amount of $\mathrm{Zn}$ is detected when the location for observation approaches the grainboundary. c, d Magnified ADF images from locations 1-5 and corresponding simulated images are provided in each projection together with schematic illustrations of the atom positions. Yellow arrows indicate the sites showing a detectable intensity by $\mathrm{Zn}$ intercalation.

minimum ${ }^{54}$ in the overall energy landscape during the transformation of $\mathrm{V}_{2} \mathrm{O}_{5}$, even though the intercalation site of $\mathrm{Zn}$ is distinct. A wider view of the rocksalt phase is provided in Supplementary Fig. 20.
To examine how consistently the experimentally acquired images of the intermediate states match the proposed crystal structures, we carried out ADF images simulations for all the images in both projections shown in Fig. 5. As readily recognized, 


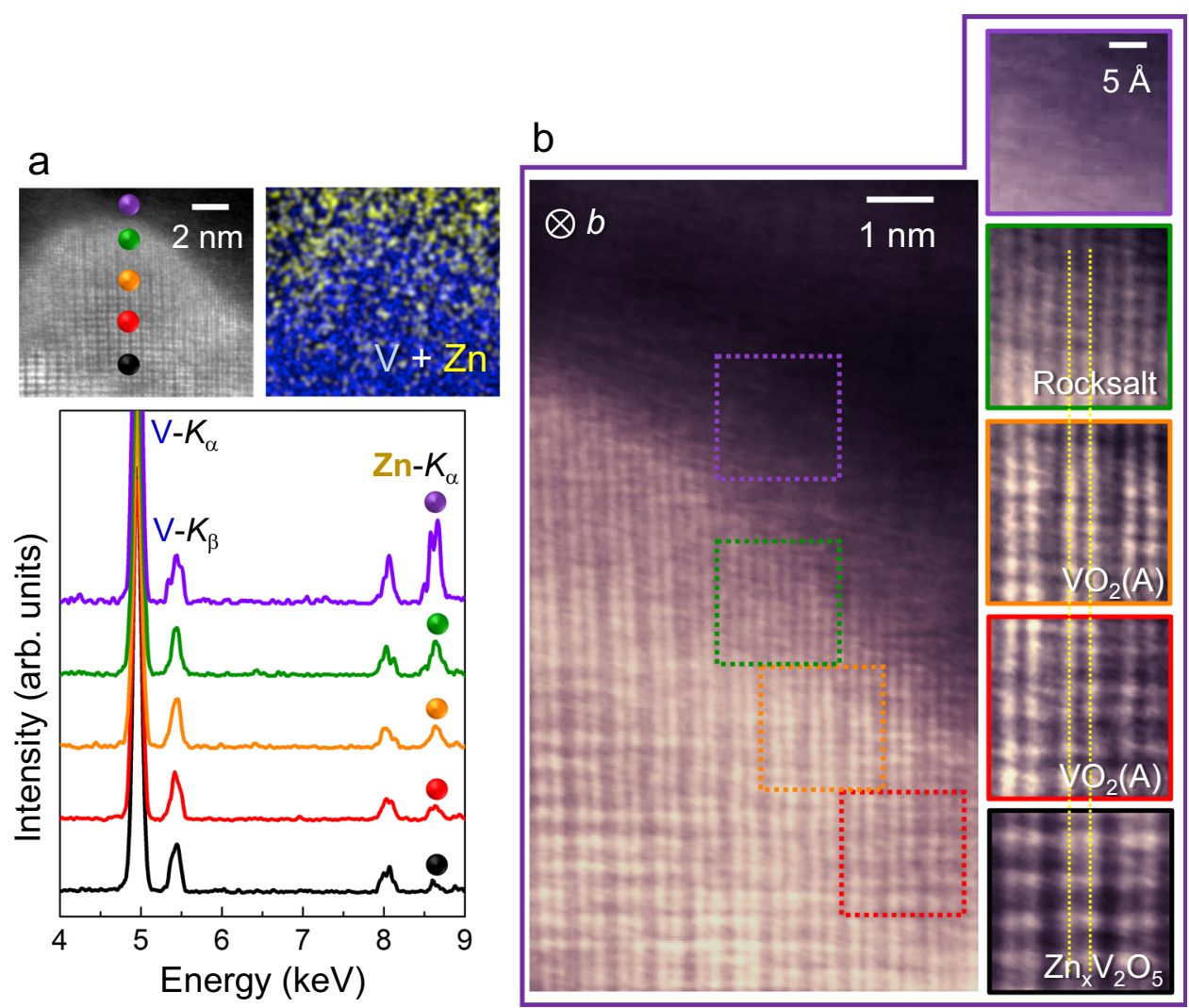

Fig. 6 Smooth transformation behavior during $\mathbf{Z n}$ insertion in the b projection. a As denoted by small spheres in color in the image, gradual increase in $\mathrm{Zn}$ concentration near the grain-boundary in a sample discharged to $0.77 \mathrm{~V}$ is verified in a series of EDS spectra along with the compositional map. $\mathbf{b}$ The magnified ADF image and the enlargements for the local regions denoted by squares demonstrate the structurally smooth and continuous phase transition without showing abrupt lattice discontinuity. A pair of yellow lines on the enlargements directly indicates the continuous arrangement of atomic columns in the phases.

good agreement between the real and simulated images is noted, providing compelling support for the multiple transformation during the discharge reaction. The occupation factor of $\mathrm{Zn}$ in the interstitial sites in each structure was properly adjusted so as to show consistent column intensity (see Supplementary Figs. 21 and 22 for the simulated images of the $\mathrm{VO}_{2}(\mathrm{~A})$-type and rocksalttype VO structures with $\mathrm{Zn}$ at the interstitial sites and Supplementary Fig. 23 for the specific Zn-occupancy factors used for the image simulations in Fig. 5). It is also noted that the transition from $\mathrm{V}_{2} \mathrm{O}_{5}$ to $\mathrm{VO}_{2}(\mathrm{~A})$ can easily take place via simple crystallographic shearing along the [011] direction (see Supplementary Fig. 24 for step-by-step schematic illustrations). Because some of the M2 interstitial sites in the $\mathrm{V}_{2} \mathrm{O}_{5}$ phase are occupied by $\mathrm{Zn}$ ions, the $\mathrm{V}$ sites in the $\mathrm{VO}_{2}(\mathrm{~A})$ phase after transformation may contain $\mathrm{Zn}$ ions. Although we presented the $\mathrm{V}$ sites merely with $\mathrm{V}$ atoms in the structure illustrations for the $\mathrm{VO}_{2}(\mathrm{~A})$ phase for simplicity (locations 3 and 4 ), both $\mathrm{V}$ and $\mathrm{Zn}$ locate in the $\mathrm{V}$ sites in the $\mathrm{VO}_{2}(\mathrm{~A})$ and rocksalt $\mathrm{VO}$ phases.

Further images were acquired along with chemical verification to clarify the continuous topotactic phase transition behavior with $\mathrm{Zn}$ insertion. Figure 6 shows a typical $b$-projection ADF image demonstrating the phase evolution during the discharge. Each enlargement represents the local atomic-column image of a region denoted by a square in color. A continuous and smooth transformation without showing clear-cut phase boundaries is observable in this image. As denoted by a pair of yellow lines in the enlargements, the projected distance between the two adjacent $\mathrm{V}$ columns does not significantly vary between the $\alpha-\mathrm{V}_{2} \mathrm{O}_{5}$, $\mathrm{Zn}_{x} \mathrm{~V}_{2} \mathrm{O}_{5}, \mathrm{VO}_{2}(\mathrm{~A})$, and $\mathrm{VO}$ phases. This notable topotactic structural correlation between the four phases is schematically depicted in detail in Supplementary Fig. 25 by comparing the crystal structures in three major orientations. In particular, a series of EDS spectra together with the composition map directly indicate the consistent increment of the $\mathrm{Zn}$ concentration with transformation from $\mathrm{Zn}_{x} \mathrm{~V}_{2} \mathrm{O}_{5}$ (black) to the low-crystallinity $\mathrm{Zn}_{y} \mathrm{~V}_{2} \mathrm{O}_{5} \cdot n \mathrm{H}_{2} \mathrm{O}$ phase (purple). To confirm the continuous phase transformations with no abrupt structural change, we acquired another ADF image in the $c$ projection and enlargements of this image along with EDS spectra and maps, as shown in Fig. 7. Seven additional sets of ADF images in the $b$ projection and composition information for the $\mathrm{Zn}$ distribution are provided in Supplementary Figs. 26-32, and they consistently support the topotactic transition behavior shown in Fig. 5.

\section{Discussion}

The present study offers several important implications regarding $\mathrm{Zn}$ insertion under an aqueous condition in $\mathrm{V}_{2} \mathrm{O}_{5}$. First, our STEM observations together with the DFT calculations provide noteworthy findings showing that many $\mathrm{Zn}$ ions unusually intercalate into the pyramidal $\mathrm{M} 2$ sites, while $\mathrm{H}_{2} \mathrm{O}$ molecules place at the $\mathrm{M} 1$ sites in $\mathrm{V}_{2} \mathrm{O}_{5}$. As the $\mathrm{V}_{2} \mathrm{O}_{5}$ framework with the $\mathrm{M} 2$-site $\mathrm{Zn}$ occupation is structurally close to $\mathrm{VO}_{2}(\mathrm{~A})$ (see Fig. 5c), this unusual occupancy and the subsequent structural analogy are believed to be energetically beneficial for facile phase transformation with a low transition barrier. The topotactic multiphase transformations observed in this work are thus likely to be responsible for the notably long cycle life behavior in $\mathrm{Zn}$ $-\mathrm{V}_{2} \mathrm{O}_{5}$ aqueous cells, as reported in recent studies, despite that the structure of the discharged $\mathrm{Zn}_{y} \mathrm{~V}_{2} \mathrm{O}_{5} \cdot n \mathrm{H}_{2} \mathrm{O}$ phase with low- 
a

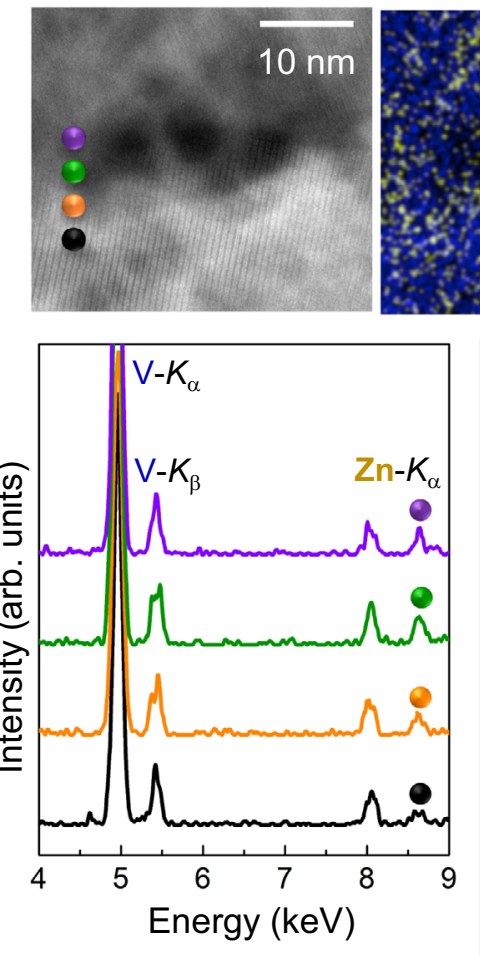

b

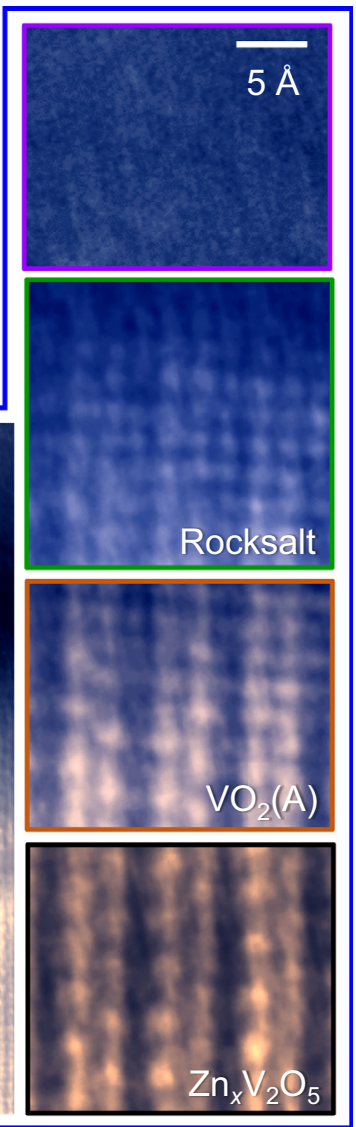


consistently show smooth transformation behavior as well. a As denoted by small spheres in color in the image, consistent variation of Zn concentration near the grain-boundary is shown in a series of EDS spectra along with the compositional map. $\mathbf{b}$ This ADF image and the enlargements for the local regions denoted by squares visualize the continuous phase transition.

crystallinity considerably differs from the initial $\mathrm{V}_{2} \mathrm{O}_{5}$ structure. It is worthwhile to mention that proton insertion could be ruled out in our work. As shown in Supplementary Fig. 33, we identified a negligible discharge capacity $\left(<4 \mathrm{mAh} \mathrm{g}^{-1}\right)$, when a sulfuric-acid solution of the same $\mathrm{pH}$ value was used for comparison. Therefore, the multiphase transformations demonstrated in this study are verified to take place during the intercalation and subsequent conversion reaction of hydrated $\mathrm{Zn}$ ions in $\mathrm{V}_{2} \mathrm{O}_{5}$.

We have identified that $\mathrm{Zn}$ ions under an aqueous condition unusually intercalate into the pyramidal interstitial sites, in addition to directly visualizing the presence of $\mathrm{H}_{2} \mathrm{O}$ in the $\mathrm{V}_{2} \mathrm{O}_{5}$ lattice. Moreover, as $\mathrm{Zn}$ insertion proceeds further, the presence of $\mathrm{VO}_{2}(\mathrm{~A})$ - and $\mathrm{VO}$-rocksalt-type intermediate phases was unveiled at atomic resolution together with the appearance of a hydrated phase for the final discharge product, showing a remarkable topotactic analogy with the intercalated $\mathrm{V}_{2} \mathrm{O}_{5}$. Our work suggests that the availability of facile smooth phase transformations via intermediate states during charge/discharge may be an important condition to retain significantly high capacity and notable cyclability in oxide-based cathodes in aqueous $\mathrm{Zn}$ ion rechargeable batteries, where many cathode materials undergo substantial structure transitions during cycling with aqueous electrolytes.

\section{Methods}

Thin-film deposition and powder synthesis. Polycrystalline $\mathrm{V}_{2} \mathrm{O}_{5}$ thin films were fabricated on glass substrates with a conductive F-doped $\mathrm{SnO}_{2}$ (FTO) coating via a simple electrodeposition process. $\mathrm{VOSO}_{4} \cdot \mathrm{nH}_{2} \mathrm{O}$ (Alfa Aesar, 99.9\%) and a mixture of high-purity ethanol and deionized water ( $50: 50$ by vol\%) were used to prepare the $0.5 \mathrm{M}$ electrolyte solution for the deposition. The film fabrication was carried out at room temperature in the solution by applying a constant potential of $2 \mathrm{~V}$ versus a $\mathrm{Ag} / \mathrm{AgCl}$ reference electrode with a potentiostat (SP-300, BioLogic). To obtain films with 500-700 nm final thickness, the duration time of the potential application was adjusted to be $2-5 \mathrm{~min}$. After deposition, the film samples were annealed at $300^{\circ} \mathrm{C}$ for $12 \mathrm{~h}$ in air to acquire crystalline $\alpha-\mathrm{V}_{2} \mathrm{O}_{5}$. Nanocrystalline $\mathrm{V}_{2} \mathrm{O}_{5}$ powder was also used to track the phase evolution by ex situ X-ray diffraction during the discharge reaction. To obtain nanocrystals, a simple dissolution-and- reprecipitation method was utilized. Micron-sized $\mathrm{V}_{2} \mathrm{O}_{5}(99.6 \%$, Alfa Aesar) was first dissolved in a $0.3 \mathrm{M}$ oxalic acid solution. This solution was stirred at $80^{\circ} \mathrm{C}$ for $5 \mathrm{~h}$ for complete dissolution of the $\mathrm{V}_{2} \mathrm{O}_{5}$ particles and subsequently dried at $100^{\circ} \mathrm{C}$ to obtain a precursor. Nanocrystalline powders were easily produced by annealing this precursor at $350^{\circ} \mathrm{C}$ for $5 \mathrm{~h}$ in air. The phase of the grown films and the powder was verified by X-ray diffractometry (Ultima IV, Rigaku) with $\mathrm{Cu} K_{\alpha}$ radiation.

Electrochemical reactions. Electrode samples were prepared by casting a slurry of $\mathrm{V}_{2} \mathrm{O}_{5}$ nanocrystals (70 wt $\%$ ), acetylene black (20 wt \%), and polyvinylidene fluoride (PVDF, $10 \mathrm{wt} \%$ ) with $N$-methylpyrrolidone (NMP) as the solvent on carbon paper. Typical loadings for the electrode coatings were $0.8-1 \mathrm{mg} \mathrm{cm}^{-2}$ of the cathode powder. $1 \mathrm{M} \mathrm{ZnSO}_{4} \cdot 7 \mathrm{H}_{2} \mathrm{O}$ (99\%, Sigma-Aldrich) dissolved in deionized water ( $\mathrm{pH}: 4.2-4.8$ ) was employed for $\mathrm{Zn}$ insertion and extraction for the aqueous condition. Galvanostatic charge and discharge were carried out with a galvanostat (SP 300 , BioLogic) under a constant current density of $0.1 \mathrm{~mA} \mathrm{~cm}^{-2}$ for the thin-film samples and $29.4 \mathrm{~mA} \mathrm{~g}^{-1}(0.1 \mathrm{C}$ rate) for the powder samples in a three-electrode beaker cell consisting of a $\mathrm{Ag} / \mathrm{AgCl}(3 \mathrm{M} \mathrm{KCl})$ reference electrode along with a $\mathrm{Pt}$ wire counter electrode. To avoid water splitting during the charge and discharge reactions, the potential range was set to be between $-0.5 \mathrm{~V}$ and $0.7 \mathrm{~V}$ versus the $\mathrm{Ag} / \mathrm{AgCl}$ reference electrode. As the film thickness could be directly measured through STEM observation, the capacity in the unit of $\mathrm{mAh} \mathrm{g}^{-1}$ was estimated by assuming that a deposited film is fully dense. Thin-film samples after the second electrochemical cycle were used for STEM observation. 
STEM, EDS, and image simulations. Samples for STEM observation were prepared by lift-out via ion-beam milling in a focused ion-beam system (Helios G4 UX, Thermo Fisher Scientific). Protective amorphous carbon and thin Pt layers were applied over the region of interest before milling. To minimize the sidewall damage and sufficiently thin the specimen for electron transparency, final milling was carried out at a voltage of $\sim 2 \mathrm{kV}$. STEM images were acquired with a transmission electron microscope (Titan cubed G2 60-300, Thermo Fisher Scientific) at $200 \mathrm{kV}$ with a spherical aberration (Cs) corrector (CEOS GmbH). The images of the discharged films were obtained from samples after the second electrochemical cycle. The optimum size of the electron probe was $\sim 1 \AA$ with a convergence semiangle of $19 \mathrm{mrad}$. The collection semiangles of the STEM detectors were set to 79.5-200 mrad for HAADF imaging, 19.1-79.5 for ADF imaging, $10.1-19.1 \mathrm{mrad}$ for $\mathrm{ABF}$ imaging, and $0-43.3$ for $\mathrm{BF}$ imaging. To avoid serious specimen damage and obtain reliable images, the beam current was adjusted to be $50-70 \mathrm{pA}$, the electron dose of which corresponds to $1.4-2.0 \times 10^{5}$ electrons $\AA^{-2}$ in our acquisition conditions. As a result, atomic columns could be sufficiently resolved in images unless several scans of an e-beam are repeated to the region of interest (see Supplementary Fig. 34). To reduce background noise and enhance the signal-tonoise ratio in STEM images ${ }^{55-60}$, the obtained raw images were filtered by using the average background subtraction filtering (ABSF) method (https://www.felmizfe.at/dm_script/hrtem-filter/). Chemical mapping with EDS was carried out in the Titan cubed G2 at $200 \mathrm{kV}$ along with four integrated silicon-drift EDS detectors at a collection solid angle of 0.7 srad. V- $K_{\alpha}(4.9 \mathrm{keV})$ and $\mathrm{Zn}-K_{\alpha}(8.6 \mathrm{keV})$ lines were selected during elemental mapping. The probe current was adjusted to be $50-100$ $\mathrm{pA}$ with a scanning time of $<250 \mathrm{sec}$. The EDS maps were low-pass filtered using Bruker ESPRIT software after reduction of background noise for better visualization. STEM images were simulated by using the Dr. Probe software ${ }^{50}$ based on the multislice algorithm. A beam energy of $200 \mathrm{keV}$, spherical aberration coefficients of $C s=0 \mathrm{~mm}, C_{5}=0 \mathrm{~mm}$, and $C_{7}=0 \mathrm{~mm}$ without coma and astigmatism, an electron probe size (FWHM) of $1 \AA$, and a slice thickness of $2 \AA$ were set during the simulations. Unless specifically mentioned, the simulations were carried out for specimen thickness of $3 \mathrm{~nm}$. Each of the real collection semiangles of the STEM detectors was also used for precise comparison with experimentally acquired images.

FTIR, XPS, and X-ray diffraction. FTIR spectra to examine the presence of water molecules in the thin films after the $\mathrm{Zn}$ insertion reaction were obtained with a FTIR spectrometer (Nicolet 6700, Thermo Fisher Scientific). The samples were dried in an oven at $60^{\circ} \mathrm{C}$ for $3 \mathrm{~h}$ before the spectroscopy. The valence state variation of $\mathrm{V}$ with $\mathrm{Zn}$ intercalation was investigated using an X-ray photoelectron spectroscope (K-Alpha XPS, Thermo Scientific) with monochromatic Al- $K_{\alpha}$ radiation and flood gun emission of $200 \mu \mathrm{A}$. REFLEX (Biobia Inc.) was utilized to simulate the powder X-ray patterns with $\mathrm{Cu} K_{\alpha}$ radiation. The parameters of the Pseudo Voigt peak shape function were set as $U=0.01, V=-0.01$, and $W=0.01$ during simulations to obtain a relatively sharp shape for clear discrimination of Bragg peaks.

DFT calculations. Ab initio DFT calculations for comparison of relative lattice energy values between supercells were carried out using the spin-polarized generalized-gradient approximation (GGA) along with the PBEsol functional revised for exchange correlation of densely packed solids and the ultrasoft pseudopotentials for ionic cores, as implemented in the CASTEP code (Biovia Inc.). To consider energetically favorable configurations of multiple pairs of a $\mathrm{Zn}$ ion and $\mathrm{H}_{2} \mathrm{O}$ molecule in the $\mathrm{V}_{2} \mathrm{O}_{5}$ lattice, sufficiently large $1 a \times 7 b \times 3 c$ supercells were constructed for geometry optimization. In addition, the GGA $+U$ method with the Hubbard $U$ parameter ( $4.0 \mathrm{eV}$ for $\mathrm{V} 3 d$ states $^{61}$ and $4.7 \mathrm{eV}$ for $\mathrm{Zn} 3 d$ states $^{62,63}$ ) was employed to account for the electron localization around $\mathrm{V}$ and $\mathrm{Zn}$ ions. Bases on our convergence testing, we found that a fairly large cutoff energy was required for precise calculations, notwithstanding comparatively high computational cost. The plane-wave basis set for the kinetic energy cutoff was thus set to be $750 \mathrm{eV}$. Relaxation of the internal coordinates for each atom was performed using the Broyden-Fletcher-Goldfarb-Shanno (BFGS) algorithm with convergence tolerances of $0.1 \mathrm{eV}^{-1}$ for the maximum ionic force, $5 \times 10^{-5} \mathrm{eV}^{-1}$ atom $^{-1}$ for the total energy, and $0.005 \AA$ for the maximum ionic displacement.

\section{Data availability}

The data that support the findings of this study are available from the corresponding author (S.-Y.C.) upon reasonable request.

Received: 2 May 2021; Accepted: 5 July 2021;

Published online: 29 July 2021

\section{References}

1. Xu, C., Li, B., Du, H. \& Kang, F. Energetic zinc ion chemistry: the rechargeable zinc ion battery. Angew. Chem. Int. Ed. 51, 933-935 (2012).
2. Pan, H. et al. Reversible aqueous zinc/manganese oxide energy storage from conversion reactions. Nat. Energy 1, 16039 (2016).

3. Gao, H. \& Goodenough, J. B. An aqueous symmetric sodium-ion battery with NASICON-structured $\mathrm{Na}_{3} \mathrm{MnTi}\left(\mathrm{PO}_{4}\right)_{3}$. Angew. Chem. Int. Ed. 55, 12768-12772 (2016)

4. Su, D., McDonagh, A., Qiao, S.-Z. \& Wang, G. High-capacity aqueous potassium-ion batteries for large-scale energy storage. Adv. Mater. 29, 1604007 (2017).

5. Gheytani, S. et al. An aqueous Ca-ion battery. Adv. Sci. 4, 1700465 (2017).

6. Liang, Y. et al. Universal quinone electrodes for long cycle life aqueous rechargeable batteries. Nat. Mater. 16, 841-848 (2017).

7. Zhang, N. et al. Rechargeable aqueous zinc-manganese dioxide batteries with high energy and power densities. Nat. Commun. 8, 405 (2017).

8. Fang, G., Zhou, J., Pan, A. \& Liang, S. Recent advances in aqueous Zn-ion batteries. ACS Energy Lett. 3, 2480-2501 (2018).

9. Tang, B., Shan, L., Liang, S. \& Zhou, J. Issues and opportunities facing aqueous zinc-ion batteries. Energy Environ. Sci. 12, 3288-3304 (2019).

10. Zhou, J. et al. Investigation of $\mathrm{V}_{2} \mathrm{O}_{5}$ as a low-cost rechargeable aqueous zinc ion battery cathode. Chem. Comm. 54, 4457-4460 (2018).

11. Zhang, N. et al. Rechargeable aqueous $\mathrm{Zn}-\mathrm{V}_{2} \mathrm{O}_{5}$ battery with high energy density and long cycle life. ACS Energy Lett. 3, 1366-1372 (2018).

12. Kundu, D., Adams, B. D., Duffort, V., Vajargah, S. H. \& Nazar, L. F. A highcapacity and long-life aqueous rechargeable zinc battery using a metal oxide intercalation cathode. Nat. Energy 1, 16119 (2016).

13. $\mathrm{Hu}$, P. et al. $\mathrm{Zn} / \mathrm{V}_{2} \mathrm{O}_{5}$ aqueous hybrid-ion batteries with high voltage platform and long cycle life. ACS Appl. Mater. Interfaces 9, 42717-42722 (2017).

14. Yan, M. et al. Water-lubricated intercalation in $\mathrm{V}_{2} \mathrm{O}_{5} \cdot \mathrm{nH}_{2} \mathrm{O}$ for high-capacity and high-rate aqueous rechargeable zinc batteries. Adv. Mater. 30, 1703725 (2018).

15. Xia, C., Guo, J., Li, P., Zhang, X. \& Alshareef, H. N. Highly stable aqueous zinc-ion storage using a layered calcium vanadium oxide bronze cathode. Angew. Chem. Int. Ed. 57, 3943-3948 (2018).

16. Ding, J. et al. Ultrafast $\mathrm{Zn}^{2+}$ intercalation and deintercalation in vanadium dioxide. Adv. Mater. 30, 1800762 (2018).

17. Shin, J., Choi, D. S., Lee, H. J., Jung, Y. \& Choi, J. W. Hydrated intercalation for high-performance aqueous zinc ion batteries. Adv. Energy Mater. 9, 1900083 (2019)

18. Li, Z. et al. Mechanistic insight into the electrochemical performance of $\mathrm{Zn} /$ $\mathrm{VO}_{2}$ batteries with an aqueous $\mathrm{ZnSO}_{4}$ electrolyte. Adv. Energy Mater. 9, 1900237 (2019).

19. Ding, J. et al. Unlocking the potential of disordered rocksalts for aqueous zincion batteries. Adv. Mater. 31, 1904369 (2019).

20. Liao, M. et al. A deep-cycle aqueous zinc-ion battery containing an oxygendeficient vanadium oxide cathode. Angew. Chem. Int. Ed. 59, 2273-2278 (2020).

21. Wan, F., Huang, S., Cao, H. \& Niu, Z. Freestanding potassium vanadates/ carbon nanotube films for ultralong-life aqueous zinc-ion batteries. ACS Nano 14, 6752-6760 (2020)

22. Zhang, S., Tan, H., Rui, X. \& Yu, Y. Vanadium-based materials: next generation electrodes powering the battery revolution? Acc. Chem. Res. 53, 1660-1671 (2020)

23. Liu, S. et al. Recent advances in vanadium-based aqueous rechargeable zincion batteries. Adv. Energy Mater. 10, 2000477 (2020).

24. Chung, S.-Y., Choi, S.-Y., Yamamoto, T. \& Ikuhara, Y. Distinct configurations of antisite defects in ordered metal phosphates: comparison between $\mathrm{LiMnPO}_{4}$ and $\mathrm{LiFePO}_{4}$. Phys. Rev. Lett. 108, 195501 (2012).

25. Gu, M. et al. Formation of spinel phase in the layered composite cathode used in Li-ion batteries. ACS Nano 7, 760-767 (2013).

26. Dixit, H., Zhou, W., Idrobo, J.-C., Nanda, J. \& Cooper, V. R. Facet-dependent disorder in pristine high-voltage lithium-manganese-rich cathode material. ACS Nano 8, 12710-12716 (2014).

27. Lin, F. et al. Surface reconstruction and chemical evolution of stoichiometric layered cathode materials for lithium-ion batteries. Nat. Commun. 5, 3529 (2014).

28. Chung, S.-Y., Choi, S.-Y., Kim, T.-H. \& Lee, S. Surface-orientation-dependent distribution of subsurface cation-exchange defects in olivine-phosphate nanocrystals. ACS Nano 9, 850-859 (2015).

29. Ryoo, H. et al. Frenkel-defect-mediated chemical ordering transition in a $\mathrm{Li}$ -Mn-Ni spinel oxide. Angew. Chem. Int. Ed. 54, 7963-7967 (2015).

30. Shukla, A. K. et al. Unravelling structural ambiguities in lithium- and manganese-rich transition metal oxides. Nat. Commun. 6, 8711 (2015).

31. Yan, P. et al. Evolution of lattice structure and chemical composition of the surface reconstruction layer in $\mathrm{Li}_{1.2} \mathrm{Ni}_{0.2} \mathrm{Mn}_{0.6} \mathrm{O}_{2}$ cathode material for lithium ion batteries. Nano Lett. 15, 514-522 (2015).

32. Yan, P. et al. Injection of oxygen vacancies in the bulk lattice of layered cathodes. Nat. Nanotechnol. 14, 602-608 (2019).

33. Findlay, S. D. et al. Robust atomic resolution imaging of light elements using scanning transmission electron microscopy. Appl. Phys. Lett. 95, 191913 (2009). 
34. Findlay, S. D. et al. Dynamics of annular bright field imaging in scanning transmission electron microscopy. Ultramicroscopy 110, 903-923 (2010).

35. Ishikawa, R. et al. Direct imaging of hydrogen-atom columns in a crystal by annular bright-field electron microscopy. Nat. Mater. 10, 278-281 (2011)

36. Findlay, S. D., Azuma, S., Shibata, N., Okunishi, E. \& Ikuhara, Y. Direct oxygen imaging with in a ceramic interface, with some observations upon the dark contrast at the grain boundary. Ultramicroscopy 111, 285-289 (2011).

37. $\mathrm{Lu}, \mathrm{X}$. et al. Lithium storage in $\mathrm{Li}_{4} \mathrm{Ti}_{5} \mathrm{O}_{12}$ spinel: The full static picture from electron microscopy. Adv. Mater. 24, 3233-3238 (2012).

38. Kim, H.-S., Jang, A., Choi, S.-Y., Jung, W. \& Chung, S.-Y. Vacancy-induced electronic structure variation of acceptors and correlation with proton conduction in perovskite oxides. Angew. Chem. Int. Ed. 55, 13499-13503 (2016).

39. Bak, J., Bae, H. B., Kim, J., Oh, J. \& Chung, S.-Y. Formation of twodimensional homologous faults and oxygen electrocatalytic activities in a perovskite nickelate. Nano Lett. 17, 3126-3132 (2017).

40. Byeon, P. et al. Atomic-scale observation of $\mathrm{LiFePO}_{4}$ and $\mathrm{LiCoO}_{2}$ dissolution behavior in aqueous solutions. Adv. Funct. Mater. 28, 1804564 (2018).

41. Heo, Y. et al. Symmetry-broken atomic configurations at grain boundaries and oxygen evolution electrocatalysis in perovskite oxides. Adv. Energy Mater. 8, 1802481 (2018).

42. Bak, J., Bae, H. B. \& Chung, S.-Y. Atomic-scale perturbation of oxygen octahedra via surface in exchange in perovskite nickelates boosts water oxidation. Nat. Commun. 10, 2713 (2019).

43. De Jesus, L. R., Andrews, J. L., Parija, A. \& Banerjee, S. Defining diffusion pathways in intercalation cathode materials: some lessons from $\mathrm{V}_{2} \mathrm{O}_{5}$ on directing cation traffic. ACS Energy Lett. 3, 2480-2501 (2018).

44. Cava, R. J. et al. The structure of the lithium-inserted metal oxide $\delta \mathrm{LiV}_{2} \mathrm{O}_{5}$. J. Solid State Chem. 65, 63-71 (1986).

45. Delmas, C., Cognac-Auradou, H., Cocciantelli, J. M., Ménétrier, M. \& Doumerc, J. P. The $\mathrm{Li}_{x} \mathrm{~V}_{2} \mathrm{O}_{5}$ system: an overview of the structure modifications induced by the lithium intercalation. Solid State Ion. 69, 257-264 (1994).

46. Braithwaite, J. S., Catlow, C. R. A., Gale, J. D. \& Harding, J. H. Lithium intercalation into vanadium pentoxide: a theoretical study. Chem. Mater. 11, 1990-1998 (1999).

47. Gershinsky, G., Yoo, H. D., Gofer, Y. \& Aurbach, D. Electrochemical and spectroscopic analysis of $\mathrm{Mg}^{2+}$ intercalation into thin film electrodes of layered oxides: $\mathrm{V}_{2} \mathrm{O}_{5}$ and $\mathrm{MoO}_{3}$. Langmuir 29, 10964-10972 (2013).

48. Mukherjee, $\mathrm{A}$. et al. Direct investigation of $\mathrm{Mg}$ intercalation into the orthorhombic $\mathrm{V}_{2} \mathrm{O}_{5}$ cathode using atomic-resolution transmission electron microscopy. Chem. Mater. 29, 2218-2226 (2017).

49. $\mathrm{Fu}, \mathrm{Q}$. et al. In operando synchrotron diffraction and in operando $\mathrm{x}$-ray absorption spectroscopy investigations of orthorhombic $\mathrm{V}_{2} \mathrm{O}_{5}$ nanowires as cathode materials for Mg-ion batteries. J. Am. Chem. Soc. 141, 2305-2315 (2019).

50. Barthel, J. Dr. Probe: a software for high-resolution STEM image simulation. Ultramicroscopy 193, 1-11 (2018).

51. Wan, N. et al. Aqueous rechargeable zinc/sodium vanadate batteries with enhanced performance from simultaneous insertion of dual carriers. Nat. Commun. 9, 1656 (2018)

52. Nam, K. W., Kim, H., Choi, J. H. \& Choi, J. W. Crystal water for high performance layered manganese oxide cathodes in aqueous rechargeable zinc batteries. Energy Environ. Sci. 12, 1999-2009 (2019).

53. Liu, H. et al. A disordered rock salt anode for fast-charging lithium-ion batteries. Nature 585, 63-67 (2020).

54. Chung, S.-Y., Kim, Y.-M., Kim, J.-G. \& Kim, Y.-J. Multiphase transformation and Ostwald's rule of stages during crystallization of a metal phosphate. Nat. Phys. 5, 68-73 (2009).

55. Krivanek, O. L. et al. Atom-by-atom structural and chemical analysis by annular dark-field electron microscopy. Nature 464, 571-574 (2010).

56. Chung, S.-Y., Choi, S.-Y., Yoon, H.-I., Kim, H.-S. \& Bae, H. B. Subsurface space-charge dopant segregation to compensate surface excess charge in a perovskite oxide. Angew. Chem. Int. Ed. 55, 9680-9684 (2016).

57. Yoon, H.-I. et al. Probing dopant segregation in distinct cation sites at perovskite oxide polycrystal interfaces. Nat. Commun. 8, 1417 (2017).

58. Kim, H.-S., Bae, H. B., Jung, W. \& Chung, S.-Y. Manipulation of nanoscale intergranular phases for high proton conduction and decomposition tolerance in $\mathrm{BaCeO}_{3}$ polycrystals. Nano Lett. 13, 1110-1117 (2018).
59. Song, C. W., Lim, J., Bae, H. B. \& Chung, S.-Y. Dissolution-induced surface roughening and oxygen evolution electrocatalysis of alkaline-earth iridates in acid. Chem 5, 3243-3259 (2019).

60. Yun, T. G., Heo, Y., Bae, H. B. \& Chung, S.-Y. Elucidating intrinsic contribution of d-orbital states to oxygen evolution electrocatalysis in oxides. Nat. Commun. 12, 824 (2021).

61. Scanlon, D. O., Walsh, A., Morgan, B. J. \& Watson, G. W. An ab initio study of reduction of $\mathrm{V}_{2} \mathrm{O}_{5}$ through the formation of oxygen vacancies and $\mathrm{Li}$ intercalation. J. Phys. Chem. C. 112, 9903-9911 (2008).

62. O’Brien, C. J., Rák, Z. \& Brenner, D. W. Free energies of (Co, Fe, Ni, Zn) $\mathrm{Fe}_{2} \mathrm{O}_{4}$ spinels and oxides in water at high temperatures and pressure from density junctional theory: results for stoichiometric $\mathrm{NiO}$ and $\mathrm{NiFe}_{2} \mathrm{O}_{4}$ surfaces. J. Phys.: Condes. Mater. 25, 445008 (2013).

63. Zasada, F., Gryboś, J., Indyka, P., Kaczmarczyk, J. \& Sojka, Z. Surface structure and morphology of $\mathrm{M}\left[\mathrm{CoM}^{\prime}\right] \mathrm{O}_{4}\left(\mathrm{M}=\mathrm{Mg}, \mathrm{Zn}, \mathrm{Fe}, \mathrm{Co}\right.$ and $\mathrm{M}^{\prime}=\mathrm{Ni}, \mathrm{Al}, \mathrm{Mn}$, Co) spinel nanaocrystals-DFT $+\mathrm{U}$ and TEM screening investigations. J. Phys. Chem. C. 118, 19085-19097 (2014).

\section{Acknowledgements}

This work was support by the Samsung Research Funding Center of Samsung Electronics, grant no. SRFC-MA1602-52. S.-Y.C. was also financially supported by the National Research Foundation of Korea, grant numbers 2019R1A2B2006133 and 2021R1A2C2006072.

\section{Author contributions}

S.-Y.C. and J.W.C. conceived and initiated the project. P.B. carried out all the experiments, electrochemical measurements, STEM analyses, specimen preparation, and image simulations. S.-Y.C. carried out the DFT calculations, assisted the STEM analyses, and wrote the paper. Y.H. and J.S. supported the experiments and electrochemical measurements. H.B.B. performed the STEM and EDS analyses and contributed the acquisition of image data. All the authors discussed the results and commented on the manuscript.

\section{Competing interests}

The authors declare no competing interests.

\section{Additional information}

Supplementary information The online version contains supplementary material available at https://doi.org/10.1038/s41467-021-24700-w.

Correspondence and requests for materials should be addressed to J.W.C. or S.-Y.C

Peer review information Nature Communications thanks the anonymous reviewer(s) for their contribution to the peer review of this work.

Reprints and permission information is available at http://www.nature.com/reprints

Publisher's note Springer Nature remains neutral with regard to jurisdictional claims in published maps and institutional affiliations.

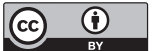

Open Access This article is licensed under a Creative Commons Attribution 4.0 International License, which permits use, sharing, adaptation, distribution and reproduction in any medium or format, as long as you give appropriate credit to the original author(s) and the source, provide a link to the Creative Commons license, and indicate if changes were made. The images or other third party material in this article are included in the article's Creative Commons license, unless indicated otherwise in a credit line to the material. If material is not included in the article's Creative Commons license and your intended use is not permitted by statutory regulation or exceeds the permitted use, you will need to obtain permission directly from the copyright holder. To view a copy of this license, visit http://creativecommons.org/ licenses/by/4.0/.

(C) The Author(s) 2021 